\title{
Periodontal Regeneration With or Without Limited Orthodontics for the Treatment of 2- or 3-Wall Infrabony Defects
}

\author{
Shigeki Ogihara* and Hom-Lay Wang ${ }^{\dagger}$
}

Background: Limited orthodontics are shown to be effective in the correction of infrabony defects. Studies have also demonstrated the efficacy of using enamel matrix derivative (EMD) with demineralized freeze-dried bone allograft (DFDBA) to treat infrabony defects. This study aims to compare the clinical efficacy of limited orthodontics combined with EMD/DFDBA in the treatment of 2- or 3-wall infrabony defects.

Methods: A randomized, parallel clinical trial was conducted in a private periodontal practice (Tokyo, Japan) between April 2004 and October 2008. Treatment period was 1 year with a 1-year follow-up. Forty-seven randomized patients, mean age of $53 \pm 10.7$ years, were allocated into two intervention groups: ortho/EMD/DFDBA $(\mathrm{n}=24)$ and EMD/DFDBA $(\mathrm{n}=$ 23). Each patient had either a 2- or 3-wall infrabony defect of $\geq 6 \mathrm{~mm}$ deep. Probing depth and clinical attachment level were measured at baseline and 1 year. The primary outcome measure was absolute change in probing depth and clinical attachment level from baseline to 1-year follow-up. The secondary outcome measure was absolute change in open probing attachment level gain and percentage defect resolution from baseline to 6-month reentry surgery. Infrabony defects were surgically treated with EMD and DFDBA 4 weeks before application of orthodontic extrusive forces. Reentry surgeries were performed at 6 months after initial surgery.

Results: Forty-seven patients were analyzed. Both treatment groups showed a significant improvement from baseline with no significant difference between the groups except for the 2-wall defects. The ortho/EMD/DFDBA group had statistically significant open probing attachment level gain (95\% confidence level, 3.18 to $4.36 ; P=0.036$ ) compared to the EMD/DFDBA group (95\% confidence level, 2.26 to 3.24) in 2-wall defects.

Conclusion: Although both treatment modalities were effective in managing 2- or 3-wall infrabony defects, limited orthodontics provided an additional benefit to EMD/DFDBA in 2-wall defects. J Periodontol 2010;81:1734-1742.

\section{KEY WORDS}

Bone remodeling, proteins; neovascularization; orthodontic extrusion; periodontal ligament; tissue engineering.

\footnotetext{
* Private practice, Tokyo, Japan.

$\dagger$ Department of Periodontics and Oral Medicine, School of Dentistry, University of Michigan, Ann Arbor, MI.
}

$1 \begin{aligned} & \text { echanical stimulation using or- } \\ & \text { thodontic extrusive force plays } \\ & \text { a critical role in periodontal tis- }\end{aligned}$ sue development. ${ }^{1}$ In a case report, Ingber ${ }^{2,3}$ demonstrated that forced eruption resulted in infrabony defect resolution accompanied by coronal positioning of intact connective tissue attachment in 1- and 2-wall infrabony defects. Brown ${ }^{4}$ too reported that orthodontic treatment could be successfully used in correcting an infrabony defect associated with a mesially inclined molar. Histologic new bone formation was observed on the tension side. Corrente et al. ${ }^{5}$ performed open flap debridement on teeth with infrabony defects before applying light continuous orthodontic forces ( 7 to $10 \mathrm{~g}$ ) to close spaces and intrude pathologically extruded teeth. Mean vertical and horizontal bone fill of approximately $1.38 \mathrm{~mm}$ was found. In addition, overall improvement in clinical attachment level (CAL) gain and probing depth (PD) reduction was also obtained. Recently, orthodontic regenerative combined therapy, which consisted of tissue regeneration followed by application of orthodontic extrusive forces, was proposed to enhance periodontal regeneration of infrabony defects. ${ }^{6}$ The advantage of this treatment approach was that new periodontal ligament fiber attachment would form before orthodontic therapy, hence facilitating transfer of orthodontic forces to bone.

doi: 10.1902/jop.2010.100127 
In an animal model, Diedrich et al. ${ }^{7}$ showed histologic periodontal regeneration of infrabony defects. Approximately $70 \%$ new root cementum formation with Sharpey's fibers insertion was observed after application of enamel matrix proteins and resorbable membranes. Ghezzi et al. ${ }^{8}$ used enamel matrix derivative (EMD) and bone grafts with collagen membranes to achieve periodontal regeneration in human infrabony defects. One year after the regenerative therapy, orthodontic forces were applied on the teeth to realign the dental arch. Significant improvements in PD and CAL were found after guided tissue regeneration. However, orthodontic therapy did not further improve these clinical parameters. Therefore, the authors concluded that orthodontic therapy was not damaging to regenerated periodontal tissues. In a case series, a collagen bovine bone mineral was used to graft vertical defects. Light continuous orthodontic forces were applied toward and through the infrabony defects 2 weeks after grafting. A mean CAL gain of $4.67 \mathrm{~mm}$ with radiographic bone fill of 2 to $3.17 \mathrm{~mm}$ and $>70 \%$ defect resolution were achieved despite orthodontically moving teeth through immature bone. ${ }^{9}$ This supports the use of tissue regeneration and orthodontics in the management of infrabony defects.

Accelerated osteogenic orthodontics, which involved corticotomy and alveolar bone augmentation before orthodontic tooth movement, was introduced by Wilcko et al. in 2001. ${ }^{10}$ This technique used the regional acceleratory phenomenon, ${ }^{11}$ which is a process that results in bursts of hard and soft tissue remodeling activated through surgical manipulation of the alveolar bone. Particulate bone graft was subsequently placed over the decorticated sites to prevent bone loss over the roots of the teeth. Therefore, accelerated osteogenic orthodontics not only drastically shortened orthodontic treatment time, but it also thickened the buccolingual bone width of the teeth involved.

The literature revealed that timing of the commencement of orthodontic treatment after periodontal surgery ranged from 10 days to 1 year, ${ }^{6,8,9,12-14}$ primarily caused by heterogeneity of study design in terms of force application, orthodontic appliance used, and type and degree of orthodontic movement. Some studies have also suggested that periodontal surgery be performed after completion of orthodontic treatment to provide a more conducive environment for periodontal regeneration. ${ }^{15,16}$ As a result, it was generally recommended that in patients with periodontal disease, orthodontic treatment should start 2 to 6 months after periodontal therapy to allow for periodontal healing and stabilization. ${ }^{17}$

Light continuous forces of 5 to $15 \mathrm{~g}$ were recommended for efficient tooth movement in a compro- mised periodontium because heavier forces might result in further loss of periodontal attachment and thus an increased crown/root ratio. ${ }^{18}$ In orthodontic extrusion of periodontally compromised teeth, constant orthodontic forces that produce an extrusion rate of $\leq 2 \mathrm{~mm}$ per month is ideal. ${ }^{19}$ Histologically, mineralization of osteoid starts 18 to 21 days after the surgical procedure, and complete bone maturation takes approximately 100 days. ${ }^{20}$ Therefore, any orthodontic tooth movement before 3 months postsurgery would be moving teeth through immature bone. Severe root resorption as a result of greater bone remodeling along the root surface is a major drawback of moving teeth through immature bone. However, faster tooth movement could be accomplished. ${ }^{21}$

Studies on the effectiveness of EMD in periodontal regeneration have demonstrated promising results. For example, Harrel et al. ${ }^{22}$ used EMD to treat infrabony defects and found significant PD reduction and CAL gains that were stable for 6 years. Sculean et al. ${ }^{23}$ also demonstrated long-term success with periodontal regeneration in infrabony defects treated with EMD. In defects that were unable to contain EMD, addition of a bone graft (e.g., demineralized freezedried bone allograft [DFDBA]) was successful in regenerating the periodontal tissues in these infrabony defects. ${ }^{24,25}$ Therefore, a combination of EMD and DFDBA was chosen for this study.

To our knowledge, no study has examined limited orthodontic treatment with EMD/DFDBA to determine its ability to treat advanced periodontal disease. Therefore, the purpose of this study is to compare the clinical efficacy of EMD/DFDBA with or without limited orthodontics in the treatment of 2- or 3-wall infrabony lesions.

\section{MATERIALS AND METHODS}

This was a randomized, parallel clinical trial conducted in a private periodontal practice (Tokyo, Japan) between April 2004 and October 2008. Forty-seven eligible, consecutive patients with chronic periodontitis (8 males and 39 females) who required periodontal treatment were recruited from a private practice to participate in this study. All patients were informed of the nature of the study, procedures involved, and potential risks and benefits associated before providing written informed consent to participate in this voluntary clinical trial. The inclusion criteria for this study were as follows: patients with chronic periodontitis, who had completed initial-phase therapy that included full-mouth scaling and root planing, occlusal adjustment where indicated, oral hygiene instructions 2 months before enrollment and at reevaluation, and a radiographic vertical defect of $\geq 6 \mathrm{~mm}$ at one or two sites. Smokers or patients who were pregnant or lactating were excluded from this study. 
At the time of screening, a comprehensive clinical and radiographic examination was conducted, in addition to obtaining a complete medical and dental history, to identify the target infrabony defect. Each patient contributed one or two infrabony defects. In total, 50 infrabony defects were identified in 47 patients.

Using a periodontal probe, ${ }^{\ddagger} \mathrm{PD}$ and CAL of the target defects were measured and recorded by one calibrated examiner (SO) at baseline and 1 -year follow-up. The PD measurement represented the greatest distance from gingival margin to base of pocket, whereas CAL is the corresponding distance from the cementoenamel junction, crown, or restoration margin to base of pocket. The primary outcome measure was absolute change in mean PD reduction and CAL gain from baseline to 1-year follow-up. The secondary outcome measure was absolute change in mean open probing attachment level (OPAL) gain and percentage defect resolution from initial surgery to 6 months reentry.

All patients rinsed presurgically with $0.12 \%$ chlorhexidine solution. After topical and local anesthesia, sulcular incisions were made before a full-thickness flap was reflected. The target infrabony defects were completely debrided and root planed with hand and ultrasonic instruments and subsequently categorized according to their morphology. The same calibrated examiner recorded direct measurements of the hard tissue, termed the "open probing attachment level." Minocycline solution, which has anticollagenase activity, was used as a root-conditioning agent for 3 minutes. The surgical site was thoroughly irrigated with sterile water before application of EMD.§ A composite graft consisting of DFDBA $\|$ mixed with minocycline and EMD (i.e., 0.25 cc of DFDBA containing $0.3 \mathrm{ml}$ of EMD) were lightly packed into the infrabony defect until a slight overfill was achieved. Flaps were reapproximated and sutured to achieve tension-free primary closure. Horizontal mattress and single interrupted sutures using a 5-0 monofilament suture ${ }^{\text {Il }}$ were placed to ensure flap adaptation and closure. The remaining EMD was gently applied onto the flap margins to enhance soft tissue wound healing.

Patients were instructed to avoid brushing and flossing at the surgical site until sutures were removed 7 days post-surgery. Minocycline for 4 days, $100 \mathrm{mg}$ per day, was prescribed. Patients were seen for postoperative treatment including plaque debridement, oral rinse with $0.12 \%$ chlorhexidine solution, and reinforcement of oral hygiene every week before completion of a restorative program.

Before patients were randomized, three defects were excluded because three patients each contributed two defects. Forty-seven randomized patients (mean age; $53 \pm 10.7$ years) with 472 -wall, 3-wall, or combination infrabony defects of $\geq 6 \mathrm{~mm}$ were allocated into two intervention groups: ortho/EMD/ DFDBA (OED) $(\mathrm{n}=24)$ (Fig. 1) and EMD/DFDBA only (ED) $(n=23)$ (Fig. 2$)$. Teeth in the OED group had extensive subgingival caries and required endodontic treatment and orthodontic extrusion before crown placement to avoid violation of biologic width. An elastic hook was placed into the root canal of the target teeth in the OED group by direct bonding for orthodontic extrusion before initial periodontal regeneration surgery.

Four weeks after the initial surgery, orthodontic extrusion was initiated in the OED group because it was thought that the enhanced angiogenesis at the surgical site might facilitate tooth movement. At this stage, remarkable soft tissue healing was obtained, especially in the interproximal area where reepithelialization was seen in most of the treated cases. Before orthodontic treatment, an occlusal metal bar (fixed orthodontic appliance) was directly bonded to the adjacent teeth to enable orthodontic extrusion and uprighting/concurrent extrusion of the target tooth. A light orthodontic force (60 to $120 \mathrm{~g}$ ) was directed occlusally or disto-occlusally for 4 weeks. Elastics were changed every 5 days to provide a constant orthodontic force on the target tooth. Excellent oral hygiene was kept by regular maintenance and reinstruction. Four weeks after orthodontic extrusion was completed, temporary stabilization with ligature and resin was provided. Six months after initial surgery, a reentry surgery was performed and hard tissue measurements (OPAL) were taken and recorded. The target teeth were restored after the surgical sites were healed. The entire treatment period was 1 year. Primary outcome was absolute change from baseline to 1-year follow-up (ED group, $\mathrm{n}=23$; OED group, $\mathrm{n}=24$ ) to prevent the influence of orthodontic fixed appliance in mean PD reduction and CAL gain. Secondary outcome was absolute change from initial surgery to 6 months reentry in mean OPAL gain.

A statistical package ${ }^{\# * *}$ was used for statistical analyses. A power analysis was conducted to determine the sample size required to attain $97 \%$ power $(\alpha$ $=0.050$; trials $=2$ ). This means that close to $100 \%$ change would be expected to yield a significant effect. The primary analysis was intention-to-treat and involved all patients who were recruited. Paired $t$ test was used to compare the mean PD, CAL, and OPAL measurements at baseline and 1-year follow-up, with significance set at $P \leq 0.05$ and expressed with $95 \%$

\footnotetext{
Williams probe, Hu-Friedy, Chicago, IL.

Emdogain, Straumann, Basel, Switzerland.

OraGRAFT, LifeNet Health, Virginia Beach, VA.

II Ethicon, Johnson \& Johnson, Somerville, NJ.

\# XLSTAT-Pro, Addinsoft USA, New York, NY.

** Microsoft Office 2007, Microsoft Corporation, Tokyo, Japan.
} 
confidence intervals $(\mathrm{CI})$. The differences between initial and postoperative values were analyzed by Wilcoxon matched-pairs signed-ranked tests and were also expressed with $95 \% \mathrm{CI}$.

\section{RESULTS}

Forty-seven eligible patients with chronic periodontitis that required periodontal treatment were recruited from a private practice between April 2004 and October 2008. Patients attended from the time of randomization (baseline) to 1 -year follow-up. The primary analysis was intention-to-treat and involved
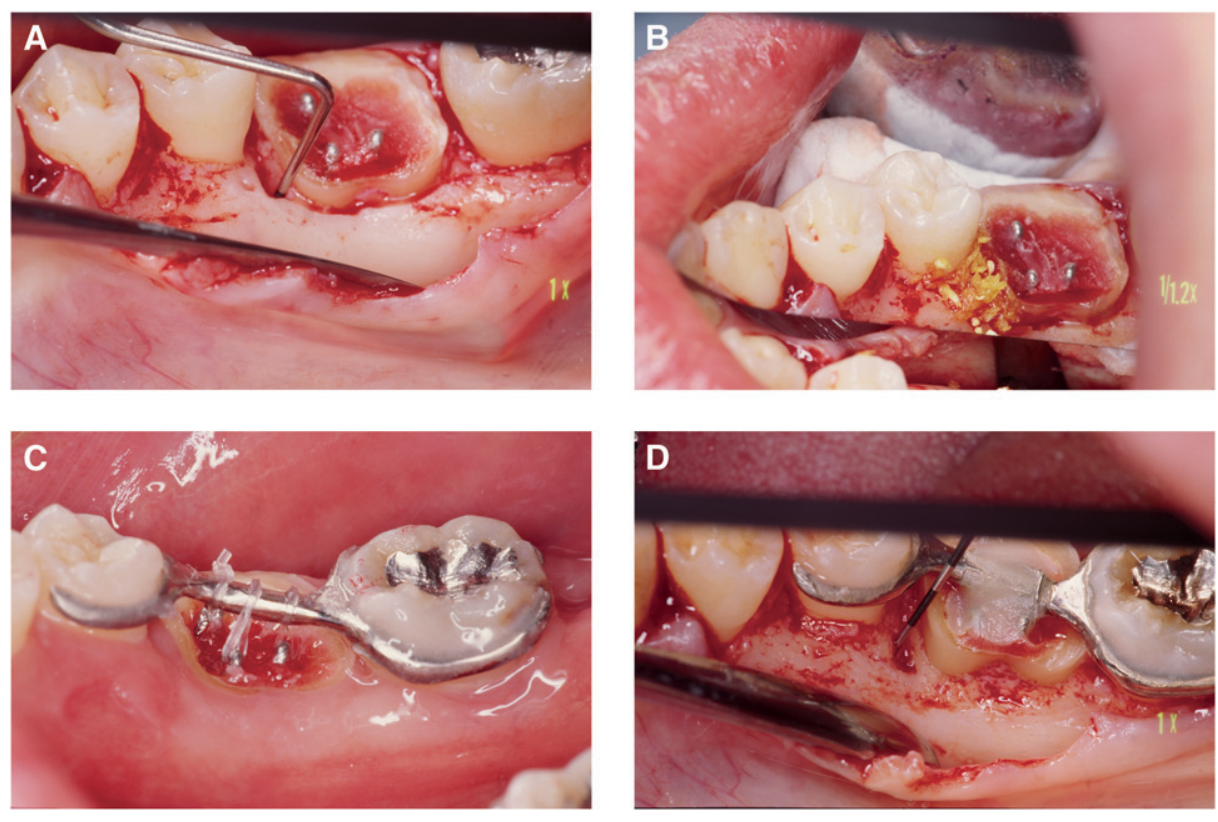

Figure I.

Combination of limited orthodontics and EMD/DFDBA for the treatment of an intrabony defect. $\boldsymbol{A})$ Extent of the intrabony defect demonstrated by the insertion of a periodontal probe. OPAL was $>/ 1 \mathrm{~mm}$. B) EMD/ DFDBA were compacted into the intrabony defect. C) Lingual view of initial extrusion at 4 weeks after initial surgery showed remarkable soft tissue healing, especially the interproximal area through enhancing angiogenesis. D) Reentry 6 months after initial surgery confirmed complete filling of the intrabony defect and reestablishment of biologic width. The OPAL was improved from $>11 \mathrm{~mm}$ to $5 \mathrm{~mm}$ (gain of $6+\mathrm{mm}$ ). all patients who were randomly assigned. No patient was lost (ED group, $n=23$; OED group, $n=24$ ). Baseline information is presented in Table 1.

There were no statistically significant differences in baseline clinical parameters between the two treatment groups $(P=0.434, P=0.891, P=0.890$ for preoperative PD, CAL, OPAL, respectively; Table 1). Both treatment groups had statistically significant PD reduction and CAL gain compared to baseline $(P<0.001)$. However, no statistically significant difference was found between the two treatment groups (Table 2). The same trend was also noted in OPAL gain and percentage of defect resolution. A significant improvement in OPAL from baseline was observed in both treatment groups $(P<0.001)$; however, no difference was found between the two groups (Table 3).

Interestingly, there was a statistically significant difference in OPAL gain between the two groups for the 2-wall defect sites. The OED group had statistically significant OPAL gain compared to the ED group. However, the absolute CAL gain did not reach statistical significance $(P=0.051$; Table $4)$. For the 3-wall defect sites, there were no significant differences between the two treatment groups (Table 5).

\section{DISCUSSION}

Overall, this study indicated that both treatments, EMD and DFDBA with or without limited orthodontics, were effective in the treatment of infrabony defects. Within 2-wall
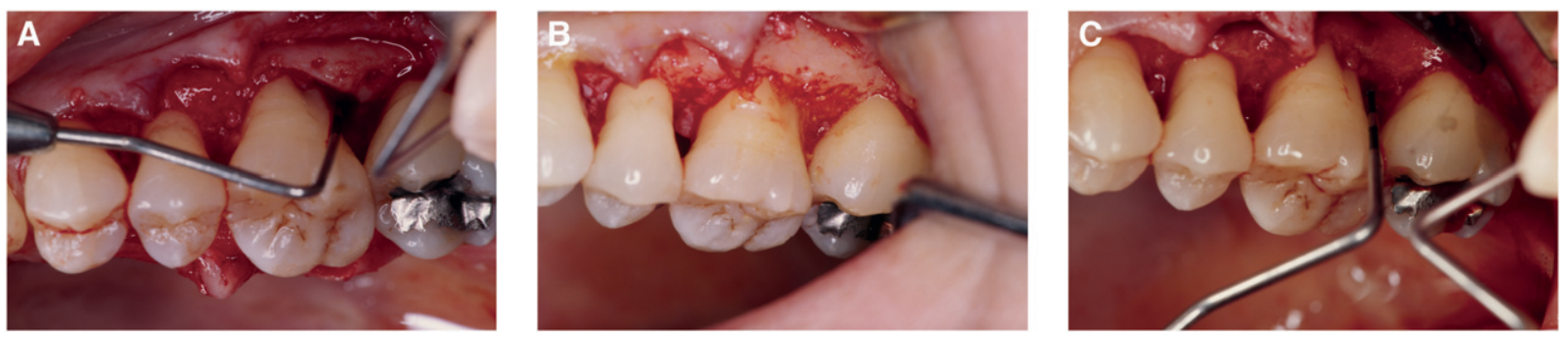

Figure 2.

EMD/DFDBA in the treatment of an intrabony defect. $\boldsymbol{A})$ Extent of the intrabony defect demonstrated by the insertion of a periodontal probe. OPAL was $6 \mathrm{~mm}$. B) EMD/DFDBA were compacted into the intrabony defect. C) Reentry 6 months after initial surgery confirmed complete filling of the intrabony defect. The OPAL was improved from $6 \mathrm{~mm}$ to $3 \mathrm{~mm}$ (gain of $3 \mathrm{~mm}$ ). 
Table I.

\section{Baseline Demographic and Clinical Characteristics for Each Study Group}

\begin{tabular}{lccc}
\hline Characteristic & $\begin{array}{c}\text { Total } \\
(\mathrm{n}=47)\end{array}$ & $\begin{array}{c}\text { EMD/DFDBA } \\
(\mathrm{n}=23)\end{array}$ & $\begin{array}{c}\text { Ortho/EMD/DFDBA } \\
(\mathrm{n}=24)\end{array}$ \\
\hline Average age (years) & $53 \pm 10.7$ & $55.6 \pm 9.4$ & $50.5 \pm 11.5$ \\
Gender & & & 20 \\
$\quad$ Female & 39 & 19 & 4 \\
$\quad$ Male & 8 & 4 & 0 \\
Lesion (walls) & 0 & 0 & 13 \\
I-wall & 21 & 8 & 7 \\
2-wall & 19 & 12 & 4 \\
3-wall & 7 & 3 & 0 \\
Combination & & & 0 \\
Tooth & 0 & 0 & 3 \\
Incisor & 0 & 0 & 21 \\
Canine & 5 & 2 & 9 \\
Premolar & 42 & 21 & 15 \\
Molar & & 11 & $6.75 \pm 1.29$ \\
Jaw & 20 & 12 & $7.29 \pm 1.20$ \\
Maxilla & 27 & $6.43 \pm 0.72$ & \\
Mandible & & $7.26 \pm 0.96$ & \\
PD (mm)* & & & \\
CAL (mm) & & & \\
\hline
\end{tabular}

No statically significant difference was found on the baseline clinical parameters between the two study groups. * $P=0.31$.

$\dagger P=0.92$.

Table 2.

Comparison of Probing Depths and Clinical Attachment Levels at Baseline and 1-Year Follow-Up Between the Two Treatment Groups

\begin{tabular}{lccc}
\hline Parameter $(\mathrm{mm})$ & EMD/DFDBA $(\mathrm{n}=23)$ & Ortho/EMD/DFDBA $(\mathrm{n}=24)$ & $P$ Value \\
\hline Baseline PD & $6.43 \pm 0.72$ & $6.75 \pm 1.29$ & \\
PD at I year & $2.74 \pm 0.54$ & $2.54 \pm 0.51$ & 0.12 \\
PD reduction & $3.70 \pm 0.76$ & $4.21 \pm 1.35$ & 0.11 \\
Change (\%)* & $57 \pm 8$ & $61 \pm 9$ & \\
95\% Cl difference & 3.36 to 3.98 & 3.67 to 4.75 & \\
Baseline CAL & $7.26 \pm 0.94$ & $7.29 \pm 1.20$ & 0.52 \\
CAL at I year & $3.74 \pm 0.69$ & $3.50 \pm 0.78$ & 0.50 \\
CAL gain & $3.50 \pm 0.79$ & $3.67 \pm 0.76$ & \\
Change (\%)* & $48 \pm 7.6$ & $50 \pm 7.1$ & \\
95\% Cl difference & 3.18 to 3.82 & 3.37 to 3.97 & \\
\hline
\end{tabular}

* Both treatment groups resulted in statistically significant PD reduction and CAL gain compared to baseline $(P<0.001)$ defect sites, the OED group had statistically significant OPAL gain $(95 \% \mathrm{CI}, 3.18$ to 4.36 ; $P=$ $0.036)$ compared to the ED group (95\% CI, 2.26 to 3.24). On the contrary, the OED group had absolute CAL gain (95\% CI, 3.19 to 4.03 ; $P=$ $0.051)$ compared to the ED group (95\% CI, 2.93 to 3.57 ). It was thus hypothesized that only OPAL gain was significant between the two groups because the measurement of CAL was dependent on the free gingival margin level and identification of the cementoenamel junction might be difficult in some of the cases. In addition, because no stent was used, measurement errors might have occurred.

In the management of 3-wall infrabony defects, both treatment modalities seemed to have similar outcomes. This could possibly be caused by the defect morphology being conducive for periodontal regeneration. A 3-wall infrabony defect allows for containment of EMD and DFDBA providing wound stability, space maintenance, and clot stabilization, hence promoting a favorable regenerative treatment outcome. ${ }^{26}$ As a result, the effect of orthodontic extrusion on eliminating these defects was inconsequential.

The success of periodontal regeneration is dependent on four key elements: 1) cells; 2 ) appropriate signals; 3 ) scaffold; and 4) blood supply. ${ }^{27}$ The establishment of new vascular networks (angiogenesis) is essential for periodontal regeneration because they are sources of nutrients for cell growth and homeostasis. During orthodontic extrusion, mechanical stresses exerted onto the alveolar bone led to activation of angiogenic growth factors, such as vascular 
Table 3.

\section{Comparison of Open Probing Attachment Levels at Baseline and 6-Month Reentry Between the Two Treatment Groups}

\begin{tabular}{lccc}
\hline & $\begin{array}{c}\text { EMD/DFDBA } \\
(n=23)\end{array}$ & $\begin{array}{c}\text { Ortho/EMD/DFDBA } \\
(n=24)\end{array}$ & $P$ Value \\
\hline Parameter $(\mathrm{mm})$ & $7.60 \pm 1.95$ & $7.40 \pm 1.92$ & \\
\hline Pretreatment OPAL & $3.39 \pm 0.84$ & $3.33 \pm 0.70$ & 0.82 \\
$\begin{array}{l}\text { OPAL at 6-month } \\
\text { reentry }\end{array}$ & $4.17 \pm 1.97$ & $4.29 \pm 1.40$ & 0.82 \\
Gain of OPAL & $53 \pm 13$ & $55 \pm 5.8$ & \\
Change $(\%) *$ & 3.36 to 4.98 & 3.73 to 4.85 & \\
$95 \%$ Cl difference &
\end{tabular}

* Both study groups resulted in statistically significant OPAL gain compared to baseline $(P<0.001)$.

Table 4.

Comparison of Probing Depths and Clinical Attachment Levels of 2-Wall Infrabony Defects at Baseline and 1-Year Follow-Up Between the Two Treatment Groups

\begin{tabular}{|c|c|c|c|}
\hline Parameter (mm) & $\begin{array}{c}\text { EMD/DFDBA } \\
\quad(n=8)\end{array}$ & $\begin{array}{l}\text { Ortho/EMD/DFDBA } \\
\qquad(n=13)\end{array}$ & $P$ Value \\
\hline Baseline PD & $6.13 \pm 0.35$ & $6.69 \pm 1.01$ & \multirow{5}{*}{0.21} \\
\hline PD at I year & $2.75 \pm 0.46$ & $2.69 \pm 0.48$ & \\
\hline PD reduction & $3.38 \pm 0.52$ & $4.00 \pm 0.91$ & \\
\hline Change (\%) & $55 \pm 7.5$ & $59 \pm 7.3$ & \\
\hline 95\% Cl difference & 3.02 to 3.74 & 3.51 to 4.49 & \\
\hline Baseline CAL & $7.25 \pm 0.71$ & $7.23 \pm 1.1$ & \multirow{5}{*}{0.051} \\
\hline CAL at I year & $4 \pm 0.53$ & $3.61 \pm 0.87$ & \\
\hline CAL gain & $3.25 \pm 0.46$ & $3.61 \pm 0.77$ & \\
\hline Change (\%) & $45 \pm 4.6$ & $51 \pm 8$ & \\
\hline 95\% Cl difference & 2.93 to 3.57 & 3.19 to 4.03 & \\
\hline Pretreatment OPAL & $6.63 \pm 1.06$ & $7.08 \pm 1.71$ & \multirow{5}{*}{$0.036 *$} \\
\hline OPAL at 6-month reentry & $4 \pm 1.20$ & $3.31 \pm 0.75$ & \\
\hline Gain of OPAL & $2.75 \pm 0.71$ & $3.77 \pm 1.09$ & \\
\hline Change (\%) & $42 \pm 1.1$ & $53 \pm 4.8$ & \\
\hline 95\% Cl difference & 2.26 to 3.24 & 3.18 to 4.36 & \\
\hline
\end{tabular}

* Ortho/EMD/DFDBA group had statistically significant OPAL gain compared to EMD/DFDBA treated site $(P<0.05)$.

endothelial growth factor (VEGF). ${ }^{28}$ VEGF production is one of the major mechanisms by which angiogenesis is closely linked to osteogenesis during bone formation and remodeling. ${ }^{29}$ Kleinheinz et al. ${ }^{30}$ also showed that VEGF activation led to more intense angiogenesis and bone regeneration. Recently, EMD was found to stimulate angiogenesis directly through endothelial cells and indirectly through production of VEGF by periodontal ligament cells. ${ }^{31}$ In addition, the use of EMD has been found to have positive effects on periodontal regeneration, such as promoting periodontal ligament cell proliferation and migration, ${ }^{32}$ and formation of new bone ${ }^{33}$ and new cementum. ${ }^{34}$ EMD can also enhance granulation tissue formation and accelerate wound closure by VEGF expression. ${ }^{31}$ Furthermore, EMD has also been demonstrated to promote soft tissue healing; ${ }^{35}$ hence, it might protect the surgical site to ensure an uneventful healing process. For all the reasons mentioned, EMD was used in this study to enhance periodontal regeneration in the infrabony defects.

In this study, 59.6\% (28 of 47) of infrabony defects were 2-wall or combination defects, whereas $44.7 \%$ (21 of 47 ) were 2-wall defects. Because of the defect morphology, containment of purely EMD without a bone substitute within the defect would be a challenge because of the fluid nature of the material. In addition, Cortellini and Tonetti ${ }^{36}$ also recommended the use of bone or bone substitutes in infrabony defects. Therefore, in this study, an allogeneic bone graft (DFDBA) was chosen because it was shown to have histologic evidence of new attachment apparatus formed in humans. ${ }^{37-39}$

Systematic reviews on regenerative periodontal therapy commonly demonstrated successful treatment outcomes with the use of bioactive agents, such as EMD, bone, or bone substitutes (e.g., DFDBA and barrier membranes)..$^{40-42}$ This observation was consistent with the findings of our study where there were significant improvements in PD and CAL between the two treatment groups. However, it is important to understand that there is great heterogeneity among the studies, and an overestimation of the overall treatment effect is possible. ${ }^{41}$

Other studies have also used regenerative procedures with orthodontic treatment and achieved favorable results. ${ }^{6-8}$ Again, there was variance within 
Table 5.

\section{Comparison of Probing Depths and Clinical Attachment Levels of 3-Wall Infrabony Defects at Baseline and 1-Year Follow-Up Between the Two Treatment Groups}

\begin{tabular}{lccc}
\hline & $\begin{array}{c}\text { EMD/DFDBA } \\
(n=12)\end{array}$ & $\begin{array}{c}\text { Ortho/EMD/DFDBA } \\
(n=7)\end{array}$ & $P$ Value \\
\hline Parameter $(\mathrm{mm})$ & $6.67 \pm 0.89$ & $7 \pm 1.91$ & \\
\hline Baseline PD & $2.58 \pm 0.51$ & $2.29 \pm 0.49$ & \\
PD at I year & $4.08 \pm 0.67$ & $65 \pm 0.14$ & 0.43 \\
PD reduction & $61 \pm 0.063$ & 3.12 to 6.3 & \\
Change (\%) & 3.76 to 4.46 & $7.57 \pm 1.61$ & \\
95\% Cl difference & $7.25 \pm 1.22$ & $3.29 \pm 0.76$ & \\
Baseline CAL & $3.42 \pm 0.67$ & $3.71 \pm 0.76$ \\
CAL at I year & $3.83 \pm 0.83$ & $49 \pm 0.060$ & \\
CAL gain & $53 \pm 0.061$ & 3.15 to 4.27 & \\
Change (\%) & 3.36 to 4.3 & $8 \pm 2.51$ & \\
95\% Cl difference & $7.83 \pm 2.24$ & $3.29 \pm 0.76$ & \\
Pretreatment OPAL & $3 \pm 0.01$ & $4.71 \pm 1.89$ & \\
OPAL 6-month reentry & $4.75 \pm 2.14$ & $58 \pm 0.073$ & \\
Gain of OPAL & $58 \pm 0.11$ & 3.31 to 6.11 & \\
Change (\%) & 3.54 to 5.96 & & \\
95\% Cl difference & &
\end{tabular}

the study designs. For example, Ghezzi et al. ${ }^{8}$ used EMD only in 3-wall infrabony defects and bone graft with collagen membrane in 1 - and 2 -wall defects. In addition, orthodontic treatment, which involved intrusion and bodily tooth movements, commenced 1 year after periodontal surgery, thus allowing time for healing so the tooth movement would have occurred in mature bone. Our study, on the contrary, used EMD and DFDBA in both 2- and 3-wall defects, and orthodontic extrusive forces were applied 1 month after periodontal surgery. Therefore, orthodontic tooth movement occurred in immature bone in our study. In an animal model, Diedrich et al. ${ }^{7}$ started distalizing the target tooth with orthodontic forces 1 month after periodontal regeneration with EMD. Again, the nature of the orthodontic tooth movements was different from those used in this study.

Excessive orthodontic extrusive forces exerted on teeth may cause root resorption and ankylosis. ${ }^{43,44}$ Determination of the appropriate extrusive forces to be applied depends on the root morphology, mainly the root diameter, length, and surface area. Therefore, if the tooth to be extruded is an incisor, $15 \mathrm{~g}$ is sufficient, whereas $60 \mathrm{~g}$ might be needed for a molar. ${ }^{45}$ If slow extrusion is desired, $30 \mathrm{~g}$ of force applied is adequate. ${ }^{46}$ However, if rapid extrusion is needed, the force applied should be increased to $50 \mathrm{~g} .^{47}$ In this study, the orthodontic extrusive forces used ranged from 60 to $120 \mathrm{~g}$ because rapid extrusion was desired with $44.7 \%$ ( 21 of 47 ) of the teeth involved being molars.
In this study, orthodontic extrusive forces were applied 4 weeks after periodontal regenerative surgery. However, it could be speculated that orthodontic extrusion alone was sufficient to treat the infrabony defects. However, Nemcovsky et al. ${ }^{48}$ found in an animal model that orthodontic forces alone were unable to regenerate completely the lost periodontium in infrabony defects because the apical migration of long junctional epithelium was unavoidable. Therefore, it was suggested that periodontal regeneration be completed before orthodontic movement. On the other hand, orthodontic treatment could be performed any time after 4 weeks. Ogihara and Marks $^{6}$ started orthodontic extrusion in a case report 8 weeks after periodontal regeneration surgery and favorable results were obtained at reentry surgery 6 months after. Ghezzi et al. ${ }^{8}$ performed orthodontic treatment 1 year after periodontal surgery, and it was found that orthodontic treatment did not have a significant influence on the regenerated defect. In this case, it could be postulated that if orthodontic treatment was started a long period of time after the suggested 4 weeks, there might not be significant changes in the clinical parameters after periodontal surgery.

Besides root and alveolar bone morphology, the direction of orthodontic tooth movement should also be considered. Orthodontic tooth movement can be classified as bodily or tipping tooth movement into an intrabony defect, moving away from an infrabony defect including extrusion and uprighting and intruding migrated elongated teeth into the reduced alveolar bone. It was found that molar uprighting could potentially lead to reduced levels of periodontal pathogens, such as Tannerella forsythensis (previously Bacteroides forsythus), Porphyromonas gingivalis, Prevotella intermedia, and Aggregatibacter actinomycetemcomitans (previously Actinobacillus actinomycetemcomitans), thus improving periodontal health. ${ }^{49}$ In animal models, intrusion of teeth to eliminate the infrabony defect led to periodontal regeneration, degradation, and remodeling of the bone graft and formation of new woven bone. ${ }^{50,51}$

There were several shortcomings in this study: short follow-up period, absence of a control group 
where open flap debridement was performed, a deficiency in racial or population diversity because of a primarily Japanese population, no radiographic analysis, and lack of stents to facilitate reproducible measurements.

\section{CONCLUSIONS}

This study shows that both treatments, EMD/DFDBA and ortho/EMD/DFDBA, were effective for the treatment of 2- or 3-wall infrabony defects within the 1 -year study period. In 2 -wall infrabony defects, use of limited orthodontics seemed to be effective in achieving attachment level gains at 6 months. However, caution is needed when interpreting these results because of the inherent limitations of the study. Therefore, more long-term randomized controlled trials are needed.

\section{ACKNOWLEDGMENTS}

The authors thank Dr. Jia-Hui Fu, Resident in Graduate Periodontics, University of Michigan, Ann Arbor, Michigan, for her assistance in preparing this manuscript. The authors report no conflicts of interest related to this study.

\section{REFERENCES}

1. Verna C, Melsen B. Tissue reaction to orthodontic tooth movement in different bone turnover conditions. Orthod Craniofac Res 2003;6:155-163.

2. Ingber JS. Forced eruption. I. A method of treating isolated one and two wall infrabony osseous defectsrationale and case report. J Periodontol 1974;45:199-206.

3. Ingber JS. Forced eruption: Part II. A method of treating nonrestorable teeth-Periodontal and restorative considerations. J Periodontol 1976;47:203216.

4. Brown IS. The effect of orthodontic therapy on certain types of periodontal defects. I. Clinical findings. J Periodontol 1973;44:742-756.

5. Corrente G, Abundo R, Re S, Cardaropoli D, Cardaropoli G. Orthodontic movement into infrabony defects in patients with advanced periodontal disease: A clinical and radiological study. J Periodontol 2003; 74:1104-1109.

6. Ogihara S, Marks $\mathrm{MH}$. Enhancing the regenerative potential of guided tissue regeneration to treat an intrabony defect and adjacent ridge deformity by orthodontic extrusive force. J Periodontol 2006;77: 2093-2100.

7. Diedrich P, Fritz U, Kinzinger G, Angelakis J. Movement of periodontally affected teeth after guided tissue regeneration (GTR) - an experimental pilot study in animals. J Orofac Orthop 2003;64:214-227.

8. Ghezzi C, Masiero S, Silvestri M, Zanotti G, Rasperini G. Orthodontic treatment of periodontally involved teeth after tissue regeneration. Int $J$ Periodontics Restorative Dent 2008;28:559-567.

9. Cardaropoli D, Re S, Manuzzi W, Gaveglio L, Cardaropoli G. Bio-Oss collagen and orthodontic movement for the treatment of infrabony defects in the esthetic zone. Int $J$ Periodontics Restorative Dent 2006;26:553-559.
10. Wilcko WM, Wilcko T, Bouquot JE, Ferguson DJ. Rapid orthodontics with alveolar reshaping: Two case reports of decrowding. Int $J$ Periodontics Restorative Dent 2001;21:9-19.

11. Frost HM. The regional acceleratory phenomenon: A review. Henry Ford Hosp Med J 1983;31:3-9.

12. Diedrich PR. Guided tissue regeneration associated with orthodontic therapy. Semin Orthod 1996;2:39-45.

13. Re S, Corrente G, Abundo R, Cardaropoli D. The use of orthodontic intrusive movement to reduce infrabony pockets in adult periodontal patients: A case report. Int J Periodontics Restorative Dent 2002;22: 365-371.

14. Re S, Corrente G, Abundo R, Cardaropoli D. Orthodontic movement into bone defects augmented with bovine bone mineral and fibrin sealer: A reentry case report. Int J Periodontics Restorative Dent 2002;22: 138-145.

15. Rabie AB, Wong RW, Hägg U. Bone induction using autogenous bone mixed with demineralised bone matrices. Aust Orthod J 1999;15:269-275.

16. Passanezi E, Janson M, Janson G, Sant'Anna AP, de Freitas MR, Henriques JF. Interdisciplinary treatment of localized juvenile periodontitis: A new perspective to an old problem. Am J Orthod Dentofacial Orthop 2007;131:268-276.

17. Gkantidis N, Christou P, Topouzelis N. The orthodontic-periodontic interrelationship in integrated treatment challenges: A systematic review. J Oral Rehabil 2010;37:377-390..

18. Melsen B, Agerbaek N, Markenstam G. Intrusion of incisors in adult patients with marginal bone loss. Am J Orthod Dentofacial Orthop 1989;96:232-241.

19. Korayem M, Flores-Mir C, Nassar U, Olfert K. Implant site development by orthodontic extrusion. A systematic review. Angle Orthod 2008;78:752-760.

20. Amler $M H$. The time sequence of tissue regeneration in human extraction wounds. Oral Surg Oral Med Oral Pathol 1969;27:309-318.

21. Nakamoto N, Nagasaka H, Daimaruya T, Takahashi I, Sugawara J, Mitani H. Experimental tooth movement through mature and immature bone regenerates after distraction osteogenesis in dogs. Am J Orthod Dentofacial Orthop 2002;121:385-395.

22. Harrel SK, Wilson TG Jr., Nunn ME. Prospective assessment of the use of enamel matrix derivative with minimally invasive surgery: 6 -year results. J Periodontol 2010;81:435-441.

23. Sculean A, Kiss A, Miliauskaite A, Schwarz F, Arweiler NB, Hannig M. Ten-year results following treatment of intra-bony defects with enamel matrix proteins and guided tissue regeneration. J Clin Periodontol 2008; 35:817-824.

24. Gurinsky BS, Mills MP, Mellonig JT. Clinical evaluation of demineralized freeze-dried bone allograft and enamel matrix derivative versus enamel matrix derivative alone for the treatment of periodontal osseous defects in humans. J Periodontol 2004;75: 1309-1318.

25. Hoidal MJ, Grimard BA, Mills MP, Schoolfield JD, Mellonig JT, Mealey BL. Clinical evaluation of demineralized freeze-dried bone allograft with and without enamel matrix derivative for the treatment of periodontal osseous defects in humans. $J$ Periodontol 2008;79:2273-2280.

26. Rosen PS, Reynolds MA. A retrospective case series comparing the use of demineralized freeze-dried bone 
allograft and freeze-dried bone allograft combined with enamel matrix derivative for the treatment of advanced osseous lesions. J Periodontol 2002;73:942949.

27. Taba M Jr., Jin Q, Sugai JV, Giannobile WV. Current concepts in periodontal bioengineering. Orthod Craniofac Res 2005;8:292-302.

28. Shiu YT, Weiss JA, Hoying JB, Iwamoto MN, Joung IS, Quam CT. The role of mechanical stresses in angiogenesis. Crit Reu Biomed Eng 2005;33:431-510.

29. Deckers MM, Karperien M, van der Bent C, Yamashita T, Papapoulos SE, Löwik CW. Expression of vascular endothelial growth factors and their receptors during osteoblast differentiation. Endocrinology 2000;141: 1667-1674.

30. Kleinheinz J, Stratmann U, Joos U, Wiesmann HP. VEGF-activated angiogenesis during bone regeneration. J Oral Maxillofac Surg 2005;63:1310-1316.

31. Schlueter SR, Carnes DL, Cochran DL. In vitro effects of enamel matrix derivative on microvascular cells. $J$ Periodontol 2007;78:141-151.

32. Hoang AM, Oates TW, Cochran DL. In vitro wound healing responses to enamel matrix derivative. $J$ Periodontol 2000;71:1270-1277.

33. Yoneda S, Itoh D, Kuroda S, et al. The effects of enamel matrix derivative (EMD) on osteoblastic cells in culture and bone regeneration in a rat skull defect. $J$ Periodontal Res 2003;38:333-342.

34. Sculean A, Stavropoulos A, Berakdar M, Windisch P, Karring T, Brecx M. Formation of human cementum following different modalities of regenerative therapy. Clin Oral Investig 2005;9:58-64.

35. Sculean A, Junker R, Donos N, Windisch P, Brecx M, Dünker N. Immunohistochemical evaluation of matrix molecules associated with wound healing following treatment with an enamel matrix protein derivative in humans. Clin Oral Investig 2003;7:167-174.

36. Cortellini P, Tonetti MS. Focus on intrabony defects: Guided tissue regeneration. Periodontol 2000 2000;22: 104-132.

37. Bowers GM, Chadroff B, Carnevale R, et al. Histologic evaluation of new attachment apparatus formation in humans. Part III. J Periodontol 1989;60: 683-693.

38. Bowers GM, Chadroff B, Carnevale R, et al. Histologic evaluation of new attachment apparatus formation in humans. Part II. J Periodontol 1989;60:675-682.

39. Bowers GM, Chadroff B, Carnevale R, et al. Histologic evaluation of new attachment apparatus formation in humans. Part I. J Periodontol 1989;60:664-674.
40. Esposito M, Grusovin MG, Papanikolaou N, Coulthard $\mathrm{P}$, Worthington HV. Enamel matrix derivative (Emdogain) for periodontal tissue regeneration in intrabony defects. A Cochrane Database Systematic Reu 2009; 7: CD003607.

41. Trombelli L, Farina R. Clinical outcomes with bioactive agents alone or in combination with grafting or guided tissue regeneration. J Clin Periodontol 2008;35(Suppl. 8):117-135.

42. Venezia E, Goldstein M, Boyan BD, Schwartz Z. The use of enamel matrix derivative in the treatment of periodontal defects: A literature review and metaanalysis. Crit Rev Oral Biol Med 2004;15:382-402.

43. Oesterle LJ, Wood LW. Raising the root. A look at orthodontic extrusion. J Am Dent Assoc 1991;122: 193-198.

44. Minsk L. Orthodontic tooth extrusion as an adjunct to periodontal therapy. Compend Contin Educ Dent 2000;21:768-770, 772, 774 passim.

45. Bach N, Baylard JF, Voyer R. Orthodontic extrusion: Periodontal considerations and applications. J Can Dent Assoc 2004;70:775-780.

46. Reitan K. Clinical and histologic observations on tooth movement during and after orthodontic treatment. Am J Orthod 1967;53:721-745.

47. Bondemark L, Kurol J, Hallonsten AL, Andreasen JO. Attractive magnets for orthodontic extrusion of crownroot fractured teeth. Am J Orthod Dentofacial Orthop 1997;112:187-193.

48. Nemcovsky CE, Sasson $M$, Beny L, Weinreb $M$, Vardimon AD. Periodontal healing following orthodontic movement of rat molars with intact versus damaged periodontia towards a bony defect. Eur J Orthod 2007;29:338-344.

49. Vanarsdall RL. Orthodontics and periodontal therapy. Periodontol 2000 1995;9:132-149.

50. da Silva VC, Cirelli CC, Ribeiro FS, et al. Intrusion of teeth with class III furcation: A clinical, histologic and histometric study in dogs. J Clin Periodontol 2008;35:807-816.

51. Araújo MG, Carmagnola D, Berglundh T, Thilander B, Lindhe J. Orthodontic movement in bone defects augmented with Bio-Oss. An experimental study in dogs. J Clin Periodontol 2001;28:73-80.

Correspondence: Dr. Shigeki Ogihara, 7-16, Adachi 3 chome, Adachi-ku, Tokyo, 1200015, Japan. Fax: 81338497483; e-mail: oshigeki@spn1.speednet.ne.jp.

Submitted March 5, 2010; accepted for publication June 26, 2010. 